\title{
The Issue of Equity: research on selection processes for educational programmes in developing countries
}

\author{
Wieby M. M. Altink and Gerard D. Thijs
}

\section{Introduction}

In recent decades most developing countries have experienced an explosive growth in primary and secondary education. The supply of qualified teachers has not been able to keep pace with the excessive demands for education, particularly in the fields of science and mathematics. This has resulted in poor quality science and mathematics education. Science and technology are powerful instruments for the development of a society. Most developing countries cannot sufficiently utilise these instruments due to a severe shortage of qualified manpower in sciencebased fields. The science education sector has, therefore, a crucial role to play in the development process.

The stagnant problems of science education can be characterised by a vicious circle with the following components: a poor primary and secondary education, resulting in a poor preparaton for higher education, which (amongst others) leads to an insufficient output of qualified teachers, which, in turn, inhibits an improvement in education.

For a number of years the Free University of Amsterdam (FUA) has been involved in projects which, among others, aim at breaking this circle. These so called Basic Science Projects are carried out in cooperation with universities in Botswana, Lesotho, Swaziland and Indonesia, referred to as the Boleswa countries. The projects can be divided into two types, corresponding to two different target points for breaking the vicious circle.

\section{Types of Programme}

The first type of project focuses on the transition from secondary school to science-based tertiary studies. These so called pre-entry science programmes offer an additional six months training for secondary school leavers in science subjects, mathematics, English and study skills. The objectives of these programmes can be specified as follows:
- to compensate for the differences in the students' backgrounds, in particular concerning the quality, the content and the depth of the science teaching at secondary schools;

- to increase the number of students in sciencebased tertiary programmes;

- to prepare the students for entry to further science-based programmes by imparting not only the necessary amount of knowledge, but also the required attitudes and practical skills.

The second type of project focuses on the group of unqualified science and mathematics teachers. These so called science teachers' upgrading programmes provide one or two year courses, both in service and/or pre-service, for secondary school teachers in science and mathematics.

The pre-entry courses have an annual attendance of about 450 students; the teachers' upgrading programmes are attended by a total of about 150 teachers. A variety of donor agencies is involved in the funding of these projects. The main conributions, however, come from the Dutch Ministry for Development Cooperation and the European Development Fund.

The educational research referred to in this article is related to the pre-entry science courses in the Boleswa countries. These courses are held in the period between secondary school examination and entry into tertiary education. In this way the courses can be conducted without extending the total educational period. Since the number of applicants for these programmes is much larger than the number of places available, some form of selection is needed. Psychologists of the FUA Department of Test Development, organised in the Educational Measurement and Evaluation in Science project, assist in developing selection strategies for the pre-entry courses. Aspects and problems of the selection procedures will be discussed next. 


\section{Selection and Second Chance}

In the selection of students for the pre-entry science courses those candidates who have the capacity to follow successfully a science-based course, have to be identified. An additional aim is to offer a second chance to students from disadvantaged schools, who because of unfavourable conditions could be considered to be underachievers relative to their talents

As stated in the 'plan of operations':

In the selection, special attention has to be paid to disadvantaged students. Though their knowledge and skills may be less compared with those of students from well established schools, efforts will be made to find out the potential abilities of all applicants.

School records and school examination results are insufficient indicators of the potential abilities of the applicants, because of the variation in the quality of the schools. Moreoever, as far as the school examinations are concerned, the Cambridge Overseas School examination results (COSC) are not even available at the start of the pre-entry courses (in January), but only two months later. Therefore, specific instruments have to be developed to select promising candidates and to provide, as far as possible, equitable opportunities for all.

For this purpose, tests can be considered useful instruments for the following reasons. First, tests enable efficient and rational decision-making. Second, at least some types of tests are less susceptible to interference from the environment than measurements of school performance. Third, tests offer the possibility of extensive scientific research [Drenth 1979; Dore 1976].

At the start of the pre-entry science projects in 1977 , tests geared to the population concerned were not available. Therefore, use had to be made of tests which had shown predictive validity with respect to mathematics and/or science subjects in other African countries in which FUA had been assisting as well. Since there was no opportunity for experimental trials, the empirical testing of the instruments had to be based on the results obtained in the actual selections. Because of restrictions imposed by practical circumstances and because of the fundamental problems related to the aims of the selection, this starting process was rather troublesome.

\section{Problems Faced in the Selection}

\section{To choose the most suitable predictors}

In the selection for the pre-entry science courses both achievement tests and ability tests have to be administered. The first type of test, which reflects concrete performance in particular subject domains, is applied because of the aim of maximum prediction. The latter type of test, which relates less to specific learning experiences, is applied on grounds of equity [Drenth 1977].

Normally a selection strategy is chosen by following an empirical approach. In that way the choice of the predictors is based on their correlation with the criterion. In the selection for the pre-entry courses such an approach is, however, not easy. In our case the criterion consists of future educational performance - in the first instance course results, but also results of subsequent educational programmes. The predictors used have a different conceptual character. Achievement predictors are less remote from the criterion and may, as such, show more validity than ability predictors, which are derived on the basis of hypothetical relations between predictor and criterion variables. Abilities need time and opportunity for development and crystallisation into concrete achievements [Ebel 1979]. Therefore, to compare the predictive power of ability and achievement predictors, long term criterion measurements have to be considered. For the pre-entry courses, however, such research is restricted, because of the limited duration of the upgrading programme and because the admission into subsequent programmes (of different character) has to be based on proficiency measures.

Results obtained in Botswana illustrate this situation. The correlations were neither impressive nor very stable, especially considering the predictions of the university performance. The results obtained, however, may also be due to several constraints in the practical situation. To mention a few: restrictions imposed by focusing on the subgroup of course students admitted into university; small sample numbers; the difference in the type and character of the course; and the characteristics of the subsequent educational programme. As to the last aspect, it should be acknowledged that promising students with unsatisfactory achievements can only be helped if certain specific requirements are met, such as: special care and attention in subsequent education.

In brief, the incongruity between 'maximum prediction' and 'equity' makes it impossible to reach both objectives without conceding to one of them. In practice some combination of several types of predictors has to be found to reach the best compromise between both the aims of selection. As traditional empirical research cannot yield this compromise, arguments relating to the conceptual value of the predictors also have to be considered. However, considering the socio-political importance of the issue of selection, it is most inconvenient to have to rely on predictors, whose validity is so hard to demonstrate. 


\section{To regulate the admission of candidates}

In view of the educational and socio-political implications of the pre-entry selections, a clear specification of the selection policy is required. Such a specification is particularly needed since the concept of equity is not unequivocally defined. On the one hand, equity may be interpreted as fair treatment of individuals. On the other hand, it may be defined as some form of group parity. In practice, however, a combination of both interpretations is not feasible.

For instance, the fair treatment of individuals relates to the use of unbiased instruments and prediction models, which do not systematically under- or overpredict the criterion performances [Cleary 1973]. Admission of the highest scoring candidate can therefore be considered equitable for single individuals. Such an approach, however, of ten has the effect of unequally representing subgroups in the sample of admitted candidates. In practice, the relative proportion of selected candidates from the so called minority groups is of ten below average. The lower the validity of the selection, the stronger this effect will be.

Arguments involved in the use of selection instruments depend to a large extent on the desired effects of the selection. Especially for interventions which aim at breaking away from the existing situation, special attention must be given to differences between societal subgroups [Thorndike 1971]. If equity is interpreted in terms of group parity, not only the 'best' candidates are admitted, but also others who have a lower probability of a 'sufficient' criterion performance. As such, an admission of candidates is based on arguments which do not strongly relate to the criterion, the predictive validity of the selection will be lowered and the treat ment of single individuals may be considered to be unfair.

The above problem could be solved by separating the processes of prediction and decision-making in the following way. The prediction of future performances is based solely on psychometric arguments. Other issues, concerning the desirability or utility of selecting various types of subgroups or individuals, are handled in the admission procedure [Novick and Peterson 1976].

In the selection for the pre-entry science course this approach seems to be useful. As in other situations [Drenth et al 1984 and 1984a], the differentiation of individuals in different societal subgroups (like: urban versus rural schools) does not seem very fruitful for discovering differences in predictor-criterion relations. To represent the complex interaction between individual and situational characteristics, a more sophisticated categorising of subgroups is apparently needed.

\section{To specify a selection model}

Problems relating to pre-entry selection refer especially to the question "to what extent can "poor" achievements be compensated by "good" capacities?" A way of dealing with this problem is given in our selection model, which is shown in Figure 1. In this model candidates are only admitted if they satisfy a certain minimum level of achievement. Above this level, the potential capacities of the applicants are honoured.

Figure 1

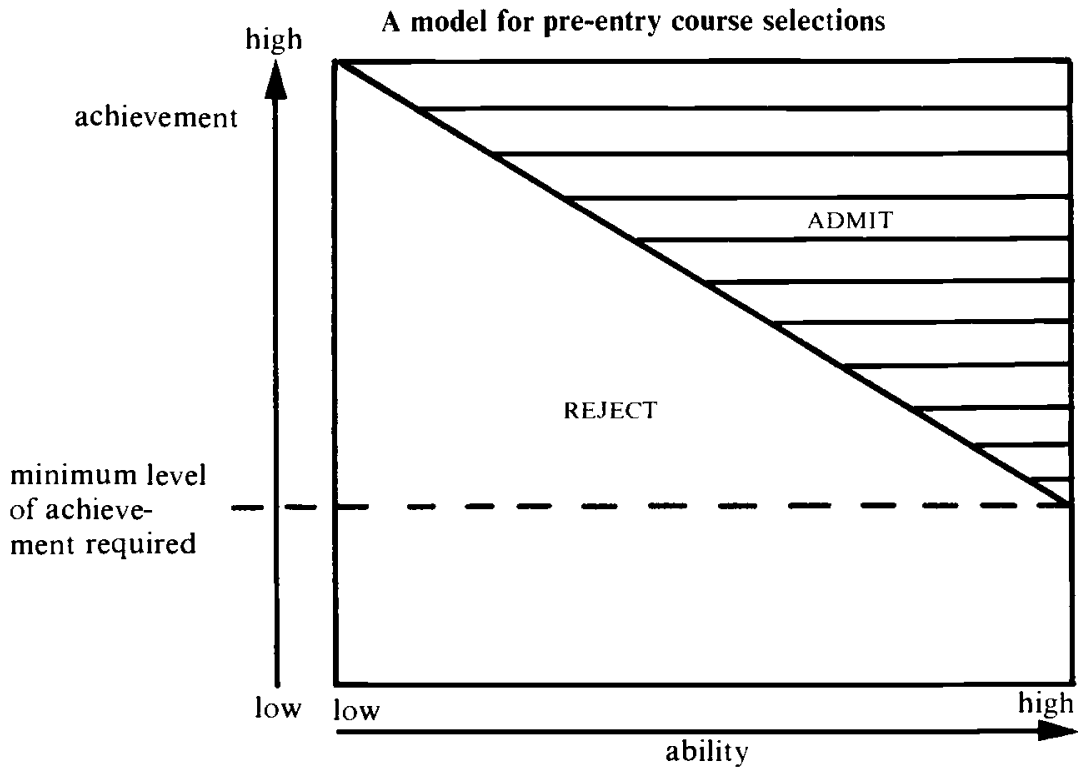




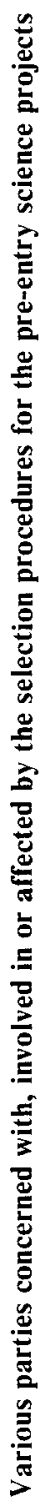

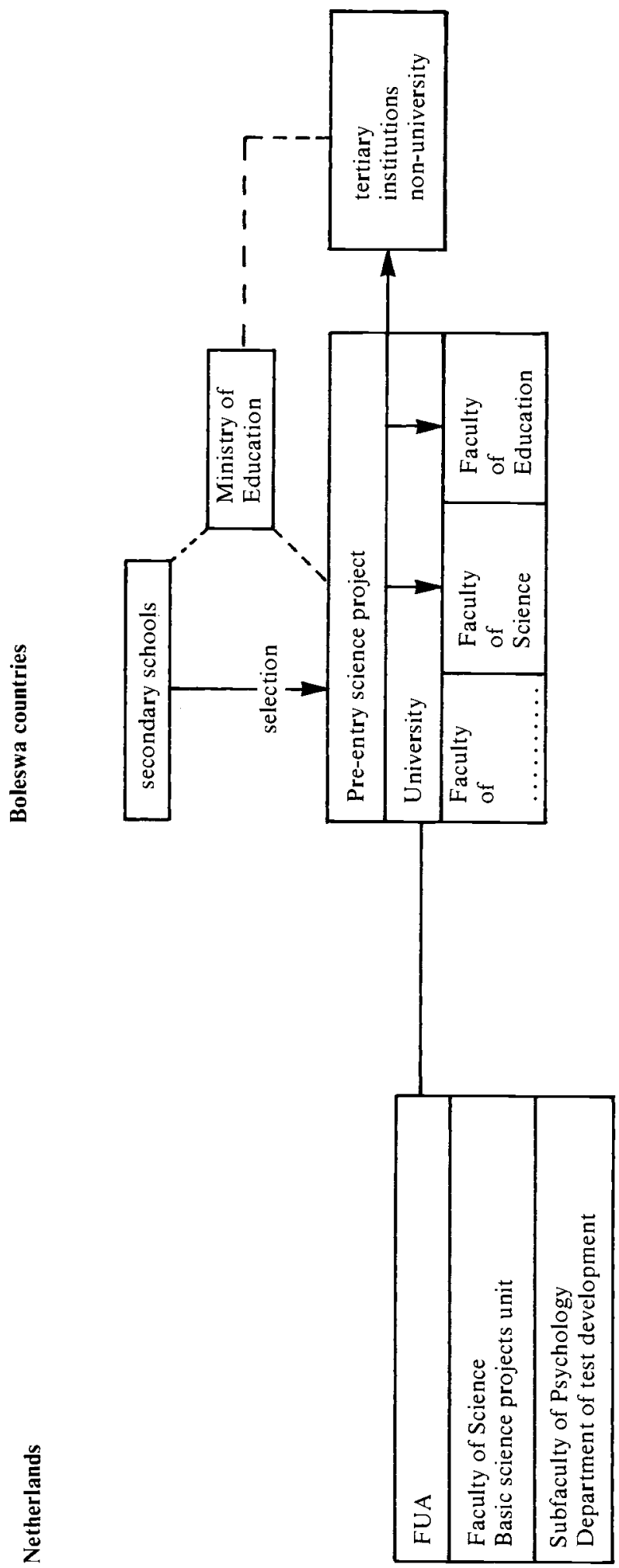


By specifying the minimum level (and possibly also a maximum level above which the applicant does not need to attend the programme), the various predictors involved, the characteristics of the compensation line, etc, the desired aims of selection can be operationalised. By assessing the success ratios of the various societal subgroups, the treatment of subgroups can also be specified. Whether we need differential procedures to predict future educational performances, has still to be investigated.

\section{To cope with different views on selection}

There are various parties concerned with, involved in, or affected by, the selection procedures for the preentry science projects. A diagram of the different parties is given in Figure 2.

The pre-entry science projects are part of a programme of cooperation between FUA and the universities in the Boleswa countries. In the agreed plans of operation, reference is made to the issue of equity. However, all parties involved have different expectations of the projects:

- Each secondary school tries to get as many of its students as possible into further education. The 'top' secondary schools argue that it is best to admit the top students, in terms of formal academic results, into the pre-entry programme. The other schools, however, welcome the fact that, besides the academic achievements, attention is paid to potential abilities of students.

- The view of the Ministry of Education regarding the pre-entry science course is largely motivated by two argnments: those of manpower requirements and of equitable distribution of educational opportunities.

- The university and other tertiary institutions are mainly interested in an increased intake and an improvement in the quality of the candidates.

- For the Free University in Amsterdam the projects are part of the FUA programme of development assistance in which "priority is given to those activities that support development that benefits large grolips of the population (the poorest sections in particular), and that increase self-reliance of the society (including the partner-university). In this policy the role of the pre-entry projects in a more equitable distribution of opportınities of tertiary education over the secondary schools and regions in the country is clearly important, in addition to interest in the production of manpower.

Apparently, not all parties involved have the same concern for equity. This situation is rather cumbersome for giving shape to a selection policy for equity, which already faces the problems mentioned above (choice of suitable predictors, anbignity of the concept of equity, and the difficulty of specifying a selection model).

\section{Problems of Management}

The so called pre-entry science teams, ie the teaching staff of the projects, visit all secondary schools each year in order to select candidates for the courses. The FUA Department of Test Development acts as the advisory unit for the selection procedures.

During the visits to the schools the teams administer tests which have been designed by, or together with, the Department of Test Development. Based on a first analysis of the test data, the teams, in consultation with the admission committees of the target institutions, select candidates for the pre-entry programmes. The test data gathered by the teams are sent for further analysis to the Netherlands. The FUA Department of Test Development then performs an extensive analysis of the test data, the school examination results, and the further educational performances of the selection candidates. On the basis of this further analysis the Department advises on amendments of selection tests and procedures. Staff members of the department have been paying short visits to the projects. They do not, however, actually participate in the school visits, the actual test sessions, the meetings of the selection committees. This situation gives rise to problems of communication and misınderstanding between the teams and the advisory test development department.

An obvious solution to this problem is to try to mobilise local experts to assist in these matters. In our case, such an approach has not been very successful. Some experts in the field of psychometrics can be found in the faculties of education of the universities and the national testing centres. However, the local experts are often overloaded by the appeals made to them from within the countries. Also, they may not be very eager to get involved in procedures with sociopolitical consequences. The situation is that the local government, who is also their employer, may prefer actions which result in immediate positive effects, without being too much concerned about the sociopolitical co-effects. This hinders the association.

Finally, we also have the impression that local psychometric experts did not see much reason for participating in activities related to the pre-entry science projects for the following reason. The projects are seen by them to be enterprises that are skillfully executed and manned, with a heavy input from abroad-teaching staff, project supervisors. In their view the problems of selection being part of the project's package should also be dealt with by the project teams and experts from abroad. 
Because of the problems involved in the mobilisation of local experts, other 'linking pins' in the management of the selection activities had to be found. In due course particular staff members of the pre-entry science teams developed into articulate agents in the field of testing. An active exchange of information on aspects of testing was triggered between these team members and the FUA Department of Test Development. Also new staff, recruited by FUA, have been trained and instructed by the psychologists on aspects of selection. The localisation of the necessary testing support within the units of the teams has clear advantages. As the teams are in the centre of the activities, they can easily obtain information needed to specify the selection procedures, through their contacts with the Ministry of Education, schools, tertiary institutions, project supervisors and psychologists at FUA.

This approach, however, does not solve all the problems of communication and lack of understanding. The teams experience the pressures of the local situation in which they have to find solutions themselves. For example, in a few cases it turns out that target institutions do not accept candidates who have very weak secondary school examination results, and who have been recommended by the teams. In such a situation, a team is inclined to pay more attention to academic achievement than to potential ability in the next selection procedure. It is rather difficult to prevent autonomous action by the team in such cumbersome situations. To advise the teams from a distance, in a realistic and adequate way, is certainly not easy.

\section{Final Remarks}

In view of the variety of problems mentioned above, it may seem questionable whether efforts in the field of selection do make sense. In our opinion, however, such efforts are certainly relevant and even rewarding. To explain this, we briefly mention some second chance effects of the pre-entry science programme.

Before the existence of the pre-entry courses, admission to the faculties of science at the universities in the Boleswa countries was granted to holders of a first or second class division COSC, with credits in English and Mathematics. The pre-entry science courses offer a second route for those students who are not formally qualified by $\operatorname{COSC}$, who can yet be admitted to the faculty of science. In 1983, a total of 227 students from the Boleswa pre-entry science courses were recommended for the faculty. Of them, 100 students had not been formally qualified in terms of COSC results. This number shows that the second chance effect is quite a considerable feature of the pre-entry courses. Therefore, to have appropriate instruments and procedures for tracing the science aptitude of potential candidates is certainly of benefit.

Nevertheless, to tackle the problems faced in the issue of fair selection, particular conditions have to be met in order to provide for good results. To mention a few:

- Our experience has been that Western scientists and psychologists called in to help in an educational programme need, in turn, the assistance of the various parties involved in the programme. For several reasons, however, such assistance may not easily be obtained. At the start of the project, the mutual cooperation between the counterparts should not only be formulāted in general terms, but be put as much as possible in operational terms.

- In addition, the cross-cultural and multidisciplinary character of our projects argues for good managerial organisation. As the parties involved may have different expectations and experiences, a spiral effect may evolve by which contradictions are emphasised instead of being ironed out. The situation where project supervisors and advisers do not experience the problems faced in the field, and where field workers have the feeling of carrying all burdens, may endanger the activities. A good managerial organisation and a clear specification of tasks and responsibilities are very much needed.

- In order to provide for the desired results of selection, discussion at several levels of the society is needed and, finally, agreement on the objectives is required. The specification of the selection policy should be as detailed as possible.

- All parties involved should have realistic expectations of the selection activities. The desired results may be visible only in the long term.

- It is important to have sufficient opportunities for research on aspects of selection, in particular longitudinal research.

None of these is a sine qua non, however; some progress is often possible, despite imperfect conditions. Still, the more they are satisfied, the more likely are the results to be good.

\footnotetext{
References

Cleary, T. A., 1973, 'Prediction of negro and white stduents in integrated colleges', Journal of Educational Measurement, vol 10, pp237-55

Dore, R., 1976, The Diploma Disease, Allen and Unwin, London
} 
Drenth, P. J. D., 1977, 'The use of intelligence tests in developing countries' in Y. H. Poortinga (ed), Basic Problems in Cross-Cultural Psychology, Swets \& Zeitlinger, Amsterdam - 1979, 'Prediction of school performances in developing nations: schoolgrades or psychological tests', Journal of Cross-Cultural Psychology, vol 8, pp49-70

-H. van der Flier, S. H. Bali, and W. C. E. Young, 1984, Contribution of Aptitude Tests to the Prediction of School Performances in Kenya: a longitudinal study, forthcoming

-H. van der Flier and I. H. Omari, 1984, Educational Selection in Tanzania, forthcoming
Ebel, R. L., 1979, Essentials of Educational Measurement, Prentice Hall, Englewood Cliffs, New Jersey

Novick, M. R., and N. S. Peterson, 1976, 'Towards equalising educational and employment opportunity', Journal of Educational Measurement, vol 13, pp77-88

Thorndike, R. L., 1971, 'Concepts of culture-fairness', Journal of Educational Measurement, vol 8, pp63-70 